\title{
NOSSO PROCESSO JUDICIAL DÁ MARGENS A DRAMAS KAFKIANOS COMO O DO BANCÁRIO JOSEPH K.?
}

\author{
Rogério Moreira Lins Pastl ${ }^{1}$
}

\begin{abstract}
RESUMO
O livro "O Processo" de Franz Kafka retrata o desconhecimento de um homem acerca de uma demanda a que está submetido. Mostra a inquietude de um ser humano buscando conhecer as razões que levaram a ser parte em um processo judicial, que se mostra totalmente desconhecido em relação à acusação e ao esdrúxulo procedimento narrado pelo autor. O presente artigo tenta contextualizar e traçar algumas semelhanças com nosso processo civil atual, onde uma grande parte dos cidadãos não tem consciência de seus direitos e de como funciona o procedimento processual. Neste sentir, o trabalho elenca alguns princípios processuais trabalhados em sala de aula e reforça a ideia de que o Direito é uma valiosíssima ferramenta de pacificação social e de erradicação das angustias humanas exteriorizadas em uma demanda judicial, o que só reforça seu caráter interpretativo e compromissado com a historicidade e com a compreensão dos fenômenos e fragilidades humanas.
\end{abstract}

\begin{abstract}
The book "The Trial" by Franz Kafka describes the ignorance of a man about a claim that he is being submitted. Shows the restlessness of a human seeking to know the reasons for being a party in a lawsuit, which appear to be totally unknown regarding to the charge and the whimsy procedure narrated by the author. This article attempts to contextualize and delineate some similarities with our current civil procedure, where a large proportion of citizens are unaware of their rights and how it works the procedure. In this sense, the work lists some procedural principles spoken in the classroom and strengthens the idea that the Law is a priceless tool for social pacification and for eradication of human anguish expressed in a lawsuit, which only reinforces his interpretative and committed character with the historicity and the understanding of the phenomena and human weakness.
\end{abstract}

Palavras-chave: Teoria geral do processo; princípios informadores; natureza hermenêutica e histórica do Direito.

\section{Breves considerações iniciais}

O Processo de Franz Kafka é um romance que mostra a condição do homem dos nossos tempos, envolvido em diversos compromissos que o impedem de compreender os fatos que acontecem a sua volta, por mais próximos que os mesmos possam ser.

Esta é uma obra clássica escrita no começo do século passado que auxilia a todo estudante - incluindo-se os professores de Direito - a conhecer e a cada vez mais exercitar a argumentação jurídica, as diversas formas de interpretação das normas e, em particular,

\footnotetext{
${ }^{1}$ Professor da disciplina de Teoria Geral do Processo, do Cesuca, Mestre em Direito, pela UFRGS. 
auxilia a melhor compreender e desenvolver os instrumentos processuais no sentido de buscar uma aproximação do Direito com a sociedade e seus cidadãos.

Um dos desafios que o texto impõe ao leitor diz respeito ao desconhecimento acerca das razões que levaram o bancário Joseph K. a ser julgado e condenado por um juízo que para ele é enigmático.

O livro relata o drama de uma pessoa fragilizada pelo que se apelidou de ambiguidade onírica, que não lhe permite distinguir entre o real e o imaginário. A bem da verdade, a obra de Franz Kafka não define com clareza os limites e extensão que acusação que foi imputada ao protagonista.

Tal circunstância dá ensejo a algumas reflexões. Pergunta-se: será que nos dias atuais, podemos ter pessoas acusadas em processos judiciais e que desconheçam total e formalmente as razões da acusação?

O questionamento pode parecer um pouco sem sentido, mas considerando nosso passado político recente - época da ditadura militar ou da revolução militar de 1964 - bem como notícias acerca da guerra que os Estados Unidos travam contra seus inimigos, em especial terroristas, e que legitimam a prisão de Guantánamo, não seria de se prestar atenção às palavras de Kafka para compreender e ressaltar a importância do processo judicial que empreste uma série de garantias aos litigantes?

Nesta mesma senda, poderíamos perquirir qual a visão que as populações dos grandes centros urbanos têm acerca das demandas processuais. Os cidadãos, quando procuram o Poder Judiciário, têm consciência de seus direitos subjetivos e de como funciona o procedimento judicial?

Estes desafios - de per si - justificam a leitura e a discussão acerca do livro "O Processo” dee Franz Kafka.

O Direito é instrumento indispensável ao homem. O Estado dá origem às leis e resolve os conflitos entre as pessoas por intermédio da prestação jurisdicional. Os comandos 
legais são genéricos, frios e impessoais, voltados a toda comunidade. O legislador, por não obter com a produção legislativa, o ideal de paz absoluta, opta pelo ideal-meio da segurança como meta de suas projeções ${ }^{2}$. O Desembargador Rui Portanova, cita, para justificar sua opção, Humberto Theodoro Júnior: como o absoluto é inatingível dentro das limitações de toda obra humana, muitas e muitas vezes o Direito tem de contentar-se com apenas atribuir segurança às situações jurídicas definitivamente consolidadas.

Conseqüência natural é que os ideais de justiça, ordem e segurança orientem o sistema jurídico assim concebido. Tradicionalmente, a paz é a segurança pela imputação da lei.

A lei serviria como ferramenta para garantir a segurança das relações e a resolução dos conflitos, oferecendo critérios de organização do Estado, como um todo.

O juiz que estamos acostumados a ver em atuação prepara-se, apenas, para declarar o direito aplicável ao caso que lhe é posto para apreciação, traduzindo a justiça almejada pelo legislador.

Deve ser dito, por outro lado, que o processo judicial não produz uma verdade absoluta. Pode-se admitir que o processo criará no mínimo duas verdades - as das partes, as quais poderiam ser chamadas de versões. Em sendo versões, o sistema deve autorizar que o juiz decida - e decida sobre o mérito da causa - com base em juízo de verossimilhança. Atuando de maneira diversa, o procedimento sempre crescerá na medida em que o sistema diminui a possibilidade de o juiz decidir com base na verossimilhança. O Direito, assim, trabalha com verdades contingentes e não necessárias como a doutrina mais tradicional prevê.

\section{A neutralidade do juiz}

Pode-se dizer que a neutralidade do juiz tem origem no Direito Romano, mais especificamente no iudex. O iudex era escolhido pelas partes e declarava o direito, exercendo,

\footnotetext{
${ }^{2}$ PORTANOVA, Rui. Motivações Ideológicas da Sentença. 4. ed. rev. Porto Alegre: Livraria do Advogado, 2000, p. 28. 
assim, a jurisdição. O praetor, que era eleito pelo povo, apreciava os litígios, formava seu juízo e expedia ordens para efetivação da decisão, exercendo, assim, seu poder de império. $\mathrm{O}$ nosso juiz se assemelha mais à figura do iudex, não sendo sua função precípua expedir ordens às partes, uma vez que declara o direito aplicável.

Não poderá, assim, o juiz manifestar-se sobre o mérito da causa sem que seja proferida sentença. Para proferir a sentença, o juiz deverá percorrer todas as fases processuais, que estão consagradas no procedimento ordinário e apenas declarar o direito.

O juiz coloca-se distante do conflito entre as partes, apenas observando a tramitação do feito, mais preocupado em resguardar os direitos procedimentais das partes ao prestar efetivamente sua jurisdição ${ }^{3}$, não importando os prejuízos que possam decorrer da morosa tramitação dos feitos judiciais. A este juiz interessa apenas a certeza do direito que as partes buscam em juízo. Para conhecer quem tem direito à determinada tutela judicial, o juiz está impedido de decidir sobre o mérito da causa com base em juízo de probabilidade ou possibilidade, sendo seu desiderato ter que buscar a certeza, que não se sabe se algum dia encontrará. O juiz "boca-da-lei" quer certeza, não julga o provável e nunca procede à execução antes da declaração.

Esses elementos poderiam expressar uma forma de garantia processual às partes, relativa à neutralidade com que o juiz analisará sua causa. Não se pode confundir juiz neutro, com juiz imparcial. Esta pseudogarantia, em verdade, vem justamente em prejuízo das próprias partes, visto que o juiz, ser humano capaz de decidir o destino das vidas dos jurisdicionados, mesmo conhecendo desde o princípio do processo judicial quem tem razão,

\footnotetext{
${ }^{3}$ Justificando a assertiva, colaciona-se posicionamento onde resta plasmada sua atualidade. Ver NERY JR., Nélson. Princípios do Processo Civil na Constituição Federal. 7. ed. São Paulo: RT, 2002, p. 152-53: “Como decorrência do princípio da paridade das partes, o contraditório significa dar as mesmas oportunidades para as partes (Chancengleichheit) e os mesmos instrumentos processuais (Waffengleichheit) para que possam fazer valer os seus direitos e pretensões, ajuizando ação, deduzindo resposta, requerendo e realizando provas, recorrendo das decisões judiciais etc. Essa igualdade de armas não significa, entretanto, paridade absoluta, mas sim na medida em que as partes estiverem diante da mesma realidade em igualdade de situações processuais. Isto quer dizer, em outras palavras, que as partes podem impugnar determinada decisão judicial recorrível, desde que preencham os requisitos de admissibilidade dos recursos, pois se, por exemplo, o autor não sucumbiu, não terá interesse em recorrer. Esse impedimento decorre de sua situação processual, já que vencedor na demanda não terá o que impugnar. Portanto, se o tribunal não conhecer de seu recurso, não terá violado o princípio do contraditório."
} 
deverá fazer de conta que não sabe a quem favorecerá sua sentença, tendo que percorrer toda a tramitação processual para só no final manifestar-se acerca da procedência da demanda.

O Professor Ovídio Baptista ${ }^{4}$ há muito vem advertindo para o fato de que o juiz está impedido, pelo sistema processual vigente, de externar sua posição acerca da demanda que lhe é dada a julgar no momento em que se convence de quem tem razão. Ele praticamente assiste o desenrolar do procedimento judicial aplicado ao caso concreto. Deverá aguardar o momento mais oportuno para fazê-lo. Vejamos as palavras do mestre:

\begin{abstract}
Ainda que o magistrado se convença, logo nas fases iniciais do litígio, que o autor tem a seu favor uma elevadíssima probabilidade de vencer a demanda, terá ele o dever de manter-se 'neutro', fingir que disso não sabe, para privilegiar o demandado, em favor do qual as expectativas de vitória sejam escassas ou nulas. O mito da neutralidade judicial torna-se um bastião inimpugnável para conservação do status quo.
\end{abstract}

A posição externada pelo professor gaúcho é a de que o juiz, mesmo convencido da probabilidade de que uma das partes tem de ver procedente sua demanda, não poderá, em face dos ditames do sistema, publicizar sua decisão. Aguardará o transcurso processual, num verdadeiro faz de conta, fingindo, como referido pelo mestre gaúcho, não saber quem sairá vencedor, impingindo-lhe, dessa maneira, verdadeiro flagelo de se ver envolvido em uma demanda judicial, a qual, no mais das vezes não é seu costume.

Não há como se considerar a neutralidade do juiz como garantia processual. $\mathrm{Na}$ verdade, a demora ou retardamento injustificado do julgamento de um feito, pode representar um dano irreparável às partes, culminando, inclusive, com a perda ou perecimento do direito material, bem como angústias e elocubrações desnecessárias.. As razões que levam ao retardamento da prestação jurisdicional muito se devem à obrigatoriedade das sentenças de mérito - ou das decisões acerca do mérito - terem de ser proferidas apenas como ato final de um procedimento judicial anacrônico.

O juiz deve estar em acordo com seu tempo e em consonância com a comunidade sobre a qual exerce sua jurisdição. Aliás, é óbvio mas precisa ser dito, ele é membro desta

\footnotetext{
${ }^{4}$ SILVA, Ovídio Araújo Baptista da. Da Sentença Liminar à Nulidade da Sentença, 2001, p. 97. 
sociedade e tem a importante missão de julgar e definir seus rumos. Não será com o tardinhamento das decisões que atenderá as necessidades de seus jurisdicionados ${ }^{5}$. As pessoas quando estão em juízo dependem justamente da decisão deste juiz, de seu sentire que estará estampado em uma sentença ou em qualquer outra decisão que realmente decida a questão posta, não apenas lhe antecipando os efeitos. A crise do direito também é uma crise de tempo e, como será visto a seguir, implica decisões céleres e efetivas, o que requer um juiz ágil e que possa lançar mão de um processo judicial capaz de preservar estes anseios. Lembrem-se as palavras de nosso maior jurista: "Justiça atrasada não é justiça, senão injustiça qualificada e manifesta".

Por outro lado, o Direito não é, pois, uma ciência exata, que se rege por fórmulas mágicas e estáticas que aplicadas encontrarão, necessariamente, um determinado resultado. Deve, sim, observar os anseios sociais, sendo que suas respostas advirão justamente da análise das leis e dos casos concretos em determinado contexto social, sempre com a atuação do juiz e das partes devidamente representadas.

Não há como esconder que o Direito Processual mantém-se fiel ao compromisso firmado com o ideal racionalista tanto exaltado na Revolução Francesa, atuando ainda hoje fundado em conceitos, resolvendo os impasses por meio de teoremas e silogismos, justamente como o mundo moderno foi concebido.

Some-se ao conteúdo hermenêutico a historicidade do Direito, fundado em pilares fortes que servem e oxigenam ao todo o sistema jurídico, em especial o processual.

\section{Dos princípios processuais}

\footnotetext{
${ }^{5}$ Moços, se vos ides medir com o direito e o crime na cadeira de juízes, começai, esquadrinhando as exigências aparentemente menos altas dos vossos cargos, e proponde-vos caprichar nelas com dobrado rigor; porque, para sermos fiéis no muito, o devemos ser no pouco. 'Qui fidelis est in minimo, et in majori fidelis est; et qui in modico iniquus est, et in majori iniquus est.'

$\ldots$

Mas justiça atrasada não é justiça, senão injustiça qualificada e manifesta. Porque a dilação ilegal nas mãos do julgador contraria o direito escrito das partes, e, assim, as lesa no patrimônio, honra e liberdade. Os juízes tardinheiros são culpados, que a lassidão comum vai tolerando. Mas sua culpa tresdobra com a terrível agravante de que o lesado não tem meio de reagir contra o delinquente poderoso, em cujas mãos jaz a sorte do litígio pendente.
}

BARBOSA, Rui. Oração aos Moços. 4ª Ed., Rio de Janeiro, Organizações Simões, 1951, p. 58-59. 
O princípio é uma proposição que funda e informa a ciência. Auxiliam na compreensão do conteúdo e extensão do comando inserido numa norma jurídica, podendo atuar como fator de integração em caso de lacunas.

O jurista português Canotilho ${ }^{6}$ afirma que "do princípio do estado de direito está a existência de um procedimento justo e adequado de acesso e realização do direito. Como a realização do direito é determinada pela conformação jurídica do procedimento e do processo, a Constituição contem princípios e normas designadas por garantias gerais de procedimento e de processo."

Vários princípios constitucionais emprestam sentido ao processo, tais como o devido processo legal, contraditório e ampla defesa, motivação das decisões, "nulla poena sine lege", que asseguram não só a observância do direito positivado, mas também garantias ao cidadão para conhecer as razões que o coloquem frente a um Juiz ou uma acusação judicial.

A obra de Franz Kafka, vista pelo enfoque processual, certamente traria conclusão diversa ao protagonista, que na visão das garantias constitucionais deveria conhecer as razões que levaram a ser acusado em juízo, quem seria o juiz responsável pela instrução do processo e seu julgamento, conhecendo de maneira antecipada do que estava sendo acusado e a qual pena estaria sujeito.

Todos estes fatores não restaram claros para Joseph K., que se vê as voltas com uma demanda judicial a qual desconhece totalmente. Inequívoco o sentimento da doutrina, no sentido de democratizar o acesso ao Poder Judiciário. Neste sentido, o ensinamento de Mauro Capelletti da década de setenta que aduz que "a acessibilidade é, ademais, promovida por mudanças que fazem os tribunais mais próximos das pessoas. Para começar, é conveniente tornar o Judiciário tão acessível fisicamente quanto possível, e, uma possibilidade é mantê-lo

\footnotetext{
${ }^{6}$ Canotilho, Joaquim Gomes. Direito Constitucional. 5. Ed. Coimbra: Livraria Almedina, 1991, p. 389. 
aberto durante a noite, de modo que as pessoas que trabalham não sejam inibidas pela necessidade de faltar ao serviço"

Esta assertiva vem ao encontro de tornar o Judiciário mais acessível à sociedade em especial aos menos instruídos. Ademais, cabe ao operador do direito papel preponderante, para não dizer decisivo, no sentido de valor o fato e seu julgamento.

\title{
Recaséns Siches ${ }^{8}$ aduz que
}

\begin{abstract}
"lo que el juez debe averiguar es si la valoración que sirvio al legislador como determinante de aquella prohibición era aplicable al nuevo caso planteado y no mencionado; paro lo cual debe también examinar o analizar los aspectos de las situaciones sociales em relaión com aquella valoración. Para llevar a cabo esos dos tipos de averiguaciones, reciprocamente relacionados, empleo um critério. Este critério ya hemos visto que no puede ser de la lógica tradicional. Este critério es, em suma, el método correcto de interpretácion jurídica y es, por tanto, el método correcto para la función jurisdiccional."
\end{abstract}

Inequívoca necessidade de realizar-se o esforço interpretativo do magistrado ao julgar o caso concreto, utilizando-se não apenas o direito positivado, mas também elementos de interpretação e adequação do caso concreto á norma.

Neste sentido, os princípios que fundam e informam o Direito deverão estar presentes no raciocínio jurídico que dará fim ao caso concreto; imprescindível, por outro lado, garantir-se à parte a observância do devido processo legal, o contraditório e a ampla defesa, a fim de que a decisão que venha a ser adotada, não carece de legalidade, legitimidade e de credibilidade, perante aos litigantes e à sociedade.

Lembremo-nos, por fim, da lição do prof. Ovídio A. Baptista da Silva, quando manifesta-se em relação á natureza científica do Direito:

"O direito, enquanto ciência hermenêutica, busca o individual, em toda sua riqueza existencial e histórica, e, mesmo admitindo que se o

\footnotetext{
${ }^{7}$ CAPELLETTI, Mauro. Acesso à justiça. Trad. Ellen Gracie Northfleet. Porto Alegre, Fabris, 1988, p. 102.

${ }^{8}$ RECASÉNS SICHES, Luis. Nueva Filosofia de la Interpretación Del Derecho. México, Porrúa, 1973, p. 186. 


\begin{abstract}
descreva como sistema, como é próprio das ciências explicativas, que buscam alcançar o domínio da natureza e a construção de princípios e regras de validade universal, sua vocação natural orienta-o para compreensão do fenômeno humano, que será sempre situado historicamente. Esta peculiariedade, comum a todo fenômeno jurídico, mostra-se ainda mais visível quando se trata do direito processual, dado que este ramo da ciência jurídica tem que tratar, necessariamente de casos individuais, onde a construção de regras gerais mostrar-se-á sempre uma tarefa limitada e precária."
\end{abstract}

\title{
3. Conclusão
}

Em conclusão, imperioso referir que o processo judicial atual, não deveria tolerar manifestações assombradas com as referidas pelo protagonista da obra literária.

Resta evidenciado que, à luz dos princípios constitucionais do processo e da forma de atuação do juiz frente ao caso concreto, não se poderia admitir a tramitação de uma denúncia ou acusação levada juízo sem que o conhecesse seu teor, a pena e os motivos pelos quais estaria sendo processado e/ou condenado.

Cintra, Grinover e Rangel ${ }^{10}$ referem que acesso à justiça não significa apenas e tão somente garantir á parte o ingresso em juízo. Esta garantia vai além, sinalizando que o litigante deve ter oportunidade de contraditório, à ampla defesa adequada ao devido processo legal e que deverá, na instrução do feito, haver possibilidade de que a parte dialogue nos autos, no sentido de expressar suas impressões acerca da causa em que está inserido.

Não pensar assim seria negar a vigência de um Estado Democrático de Direito.

\footnotetext{
${ }^{9}$ BAPTISTA DA SILVA, Ovídio A. Teoria Geral do Processo Civil. 6a. ed., S. Paulo: Rev. Tribunais, 2011, p. 11.

${ }^{10}$ CINTRA, Antônio Carlos de Araújo; GRINOVER, Ada Pellegrini; RANGEL, Candido. Teoria Geral do Processo. 25. ed. São Paulo: Malheiros.
} 


\section{REFERÊNCIAS BIBLIOGRÁFICAS:}

BARBOSA, Rui. Oração aos Moços. $4^{\text {a }}$. Ed., Rio de Janeiro, Organizações Simões, 1951

CANOTILHO, Joaquim Gomes. Direito Constitucional. 5. Ed. Coimbra: Livraria Almedina, 1991.

CAPELlETTI, Mauro. Acesso à justiça. Trad. Ellen Gracie Northfleet. Porto Alegre, Fabris, 1988.

CINTRA, Antônio Carlos de Araújo; GRINOVER, Ada Pellegrini; RANGEL, Candido. Teoria Geral do Processo. 25. ed. São Paulo: Malheiros.

NERY JR., Nélson. Princípios do Processo Civil na Constituição Federal. 7. ed. São Paulo: RT, 2002

PORTANOVA, Rui. Motivações Ideológicas da Sentença. 4. ed. rev. Porto Alegre: Livraria do Advogado, 2000.

RECASÉNS SICHES, Luis. Nueva Filosofia de la Interpretación Del Derecho. México, Porrúa, 1973.

SILVA, Ovídio Araújo Baptista da. Da Sentença Liminar à Nulidade da Sentença, Rio de Janeiro: Forense, 2001.

. Teoria Geral do Processo Civil. 6 a . ed., S. Paulo: Rev. Tribunais, 2011 